\title{
Kinetics of Aldol Condensation of Furfural with Acetone Catalyzed by 1,8-Diazabicyclo[5.4.0]undec-7-ene
}

\author{
Chengjun Jiang1, Lin Cheng1, Guilin Cheng2* \\ ${ }^{1}$ Department of Chemical \& Biological Engineering, Zhejiang University of Science and Technology, Hangzhou, China \\ ${ }^{2}$ Academy of Chinese Medical Sciences, Zhejiang Chinese Medical University, Hangzhou, China \\ Email: *cheng_guilin@163.com
}

How to cite this paper: Jiang, C.J., Cheng, L. and Cheng, G.L. (2018) Kinetics of Aldol Condensation of Furfural with Acetone Catalyzed by 1,8-Diazabicyclo[5.4.0]undec7-ene. Journal of Materials Science and Chemical Engineering, 6, 65-73. https://doi.org/10.4236/msce.2018.62005

Received: January 29, 2018

Accepted: February 25, 2018

Published: February 28, 2018

Copyright $\odot 2018$ by authors and Scientific Research Publishing Inc. This work is licensed under the Creative Commons Attribution International License (CC BY 4.0).

http://creativecommons.org/licenses/by/4.0/

\begin{abstract}
The kinetics of 1,8-diazabicyclo[5.4.0]undec-7-ene (DBU)-catalyzed aldol condensation of furfural with acetone was investigated under free solvent conditions from $50^{\circ} \mathrm{C}-90^{\circ} \mathrm{C}$. The highest yield of 1,4-pentandien-3-on-1,5-di-furanyl catalyzed by DBU reached $98.0 \%$ under optimized conditions. According to the kinetic analysis, the reaction order of furfural was estimated as 1.0, the apparent activation energy was $17.7 \mathrm{~kJ} \cdot \mathrm{mol}^{-1}$, and the pre-exponential factor was $2.67 \mathrm{~L} \cdot \mathrm{min}^{-1}$ in fitting with the Arrhenius equation, which explains the high efficiency of the DBU catalyst. DBU-catalyzed aldol condensation with free solvent offers an alternative route to simplify aldol condensation and separation into a single step.
\end{abstract}

\section{Keywords}

Kinetics, Aldol Condensation, DBU, Liquid Fuels

\section{Introduction}

The global usage of petroleum and other liquid fuels is projected to grow from 90 million barrels per day (b/d) in 2012 to 100 million b/d in 2020 and 121 million $\mathrm{b} / \mathrm{d}$ in 2040 [1]. Most of the growth in liquid fuel consumption is projected to occur in the transportation and industrial sectors. The environmental impacts associated with greenhouse gas (GHG) emissions from the combustion of fossil fuels have motivated a search for new technologies enabling the sustainable production of transportation fuels [2]. Among these technologies, aldol condensation can be applied to biomass-derived feedstocks to upgrade small oxygenates to larger ones that are more similar in molecular size to those in conventional 
fuels. Aldol condensation has several advantages compared to fast pyrolysis, liquefaction, and Fischer-Tropsch synthesis. For example, extreme temperatures and pressures, necessary for Fischer-Tropsch synthesis and liquefaction, are not required. In addition, the process has much greater selectivity compared to fast pyrolysis, which produces a wide variety of products. Furfural and acetone are readily available chemicals that can be produced by biomass hydrolysis [3]. Aldol condensation of furfural with acetone and hydrodeoxygenation are considered effective integration steps towards the production of liquid fuels. However, aldol condensation of furfural with acetone is very complicated, including reactions by self-condensation and the mixed condensation of aldehydes and ketones. Aldol condensation occurs in the presence of basic catalysts, usually $\mathrm{NaOH}$ [4]. However, the use of these catalysts increases environmental pollution. Solid catalysts are recognized as promising alternatives for aldol condensation of furfural with acetone. Selectivity is the most important factor in this reaction. The conversion of furfural reaches $99.6 \%$ after reacting at $85^{\circ} \mathrm{C}$ for $8 \mathrm{~h}$, while the selectivities of furfural-acetone (FAc) and di-furfural-acetone (F2Ac) are $42.2 \%$ and $57.1 \%$, respectively, when $20 \% \mathrm{MgO} / \mathrm{NaY}$ is used as the catalyst [5]. For an $\mathrm{MgO}-\mathrm{ZrO}_{2}$ catalyst loaded on a mesoporous carbon material [6], the catalytic performance is greatly enhanced. When graphite with a large specific surface area is used as a catalyst carrier, the conversion of furfural reaches $96.5 \%$ and the selectivity of the condensation product reach $87.8 \%$. Subsequently, a biphasic solid catalyst was prepared using a cubic c-MgxZr1- $\mathrm{xO}_{2}-\mathrm{x}$ solid solution and agglomerated cubic c-MgO by an alcohol gel method; it showed significantly increased catalytic effects toward furfural condensation with acetone [7]. The catalytic effects of a solid catalyst based on $\mathrm{MgO}-\mathrm{ZrO}_{2}, \mathrm{NaY}$ were studied. The selectivity of the mono-condensed product was higher, which was attributed to the decreased cage size in the faujasite structure [8]. Molecular sieves [9] [10] [11] and metalorganic frameworks (MOFs) were also used to catalyze the condensation reaction between furfural and acetone [12]. The conversion of furfural and the selectivity of furfural to acetone were $38.5 \%$ and $79.5 \%$, respectively, at $100^{\circ} \mathrm{C}$ using an HBEA zeolite as catalyst. For furfural and acetone condensation catalyzed by biphasic catalysis [13], the ideal mono-condensation products and double-condensation products were obtained by adjusting the ratio of reagents and the reaction conditions [14]. 1,8-Diazabicyclo[5.4.0]undec-7-ene (DBU), a type of amidine compound, is used in organic synthesis reactions as a non-nucleophilic basic catalyst. We found that DBU was an excellent catalyst for aldol condensation. Therefore, the kinetics of DBU-catalyzed aldol condensation must be studied to understand the mechanism underlying the high yield achieved with $\mathrm{DBU}$, which may assist in reducing future pressure regarding product separation and catalyst recycling. In this study, we first optimized the conditions for aldol condensation using DBU as a catalyst and then examined the kinetics of the DBU-catalyzed aldol condensation of furfural and acetone. The reaction rate constants $(\mathrm{k})$ at five temperature levels were determined and the apparent acti- 
vation energy $(\mathrm{Ea})$ was calculated. These kinetic parameters may assist in elucidating the reaction mechanism of product formation with DBU in further research.

\section{Experimental}

\subsection{Materials}

DBU (99\%), furfural, and acetone (Analytical reagent) were purchased from Energy Chemistry Co., Ltd. All the chemicals were used as received from suppliers.

\subsection{Aldol Condensation of Furfural with Acetone by DBU Catalysis}

In a typical synthesis, acetone $(58.0 \mathrm{~g}, 1.0 \mathrm{~mol})$, furfural $(9.6 \mathrm{~g}, 0.1 \mathrm{~mol})$, and DBU $(0.152 \mathrm{~g}, 0.001 \mathrm{~mol})$ were sealed in a $100-\mathrm{mL}$ laboratory-scale batch reactor equipped with a blender, sampling line with cooling coil, temperature controller, and stirring rate controller (Figure 1).

\subsection{Kinetics Experiments}

Kinetics experiments were performed in the reaction system with a sampling line. The molar ratio of acetone to furfural and the catalyst amount were both fixed. The total reaction volume was considered constant $(80 \mathrm{~mL})$ during the reaction, because the volume of samples withdrawn for kinetics experiments was less than $1 \%$ of the total volume. Samples of $0.5 \mathrm{~mL}$ were withdrawn from the mixed reaction system at intervals and immediately injected into the GC analyzer.

\subsection{Analysis of Samples}

Analysis of the reaction products was performed using a FuLi 9790A GC unit equipped with a flame ionization detector using a HP-5 capillary column (30 $\mathrm{m} / 0.32 \mathrm{ID} / 0.25 \mathrm{~m})$. The obtained products were identified based on the standard reference compounds and GC-mass spectrometry (MS) analysis of the representative product samples. The conversion of furfural and selectivities to $F A$ and $F 2 A$ were calculated by the following formul as:

$$
\begin{gathered}
\text { Conversion }(\%)=\frac{\text { moles of furfural consumed }}{\text { moles of furfural input }} \times 100 \% \\
\text { Selectivity to } \mathrm{FA}(\%)=\frac{\text { moles of } F A}{\text { moles of furfural consumed }} \times 100 \% \\
\text { Selectivity to } F 2 A(\%)=\frac{2 \times \text { moles of } F 2 A}{\text { moles of furfural consumed }} \times 100 \%
\end{gathered}
$$

Chromatogram for typical products shown as Figure 2.

\section{Results and Discussion}

Aldol condensation of furfural with acetone requires activation by a catalyst to achieve a high yield. Here, DBU was used as a homogeneous catalyst. All the 


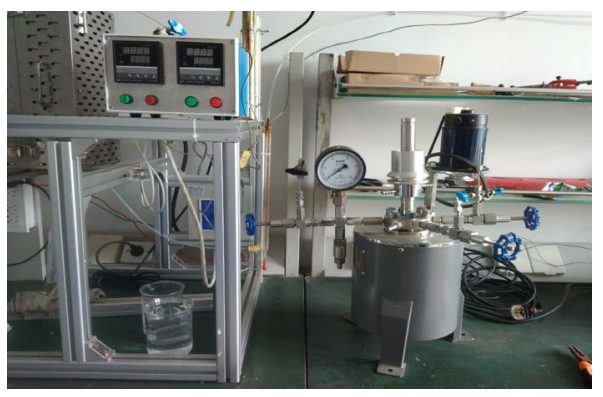

Figure 1. The equipment used for synthesis.

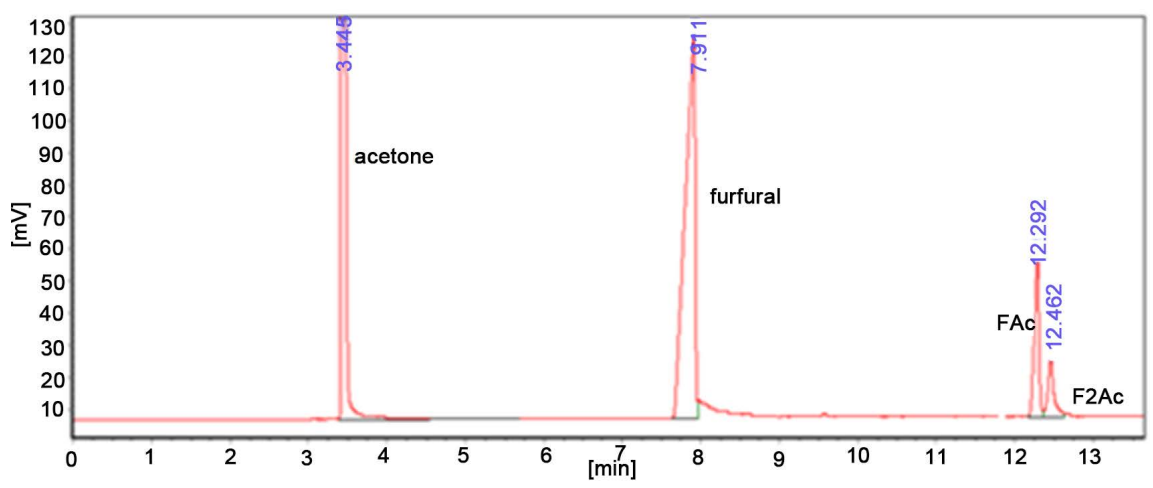

Figure 2. Chromatogram for typical products.

reactions were performed in closed systems, from which higher yields could be obtained. The effects of the main reaction conditions on the FAc yield were explored in the subsequent experiments. The kinetic parameters were then determined based on reaction data from the optimal conditions.

\subsection{Effect of the Molar Ratio of Acetone to Furfural on the Selectivity}

The molar ratio of acetone to furfural is one of the most important variables affecting the FAc yield in aldol condensation. One mole of furfural theoretically requires at least one mole of acetone; for a reaction in which less acetone is present than furfural, F2Ac is easily formed. In this reaction system, acetone was in excess compared to furfural in order to form FAc with high selectivity. As shown in Figure 3, the FAc yield is increased as the molar ratio of acetone to furfural is increased in the range from $0.5: 1$ to $8: 1$. The highest selectivity (98.5\%) is achieved beginning at the molar ratio of $4: 1$; the yield increases little in the molar ratio range of $4: 1$ to $8: 1$, in contrast to the increasing concentration of acetone. This phenomenon indicates that excessive acetone increases the selectivity of FAc. In order to ensure the selectivity of the reaction, the study of kinetics was performed with a molar ratio of acetone to furfural of 10:1.

\subsection{Kinetic Model}

The overall model for aldol condensation of furfural with acetone is described in Scheme 1. 


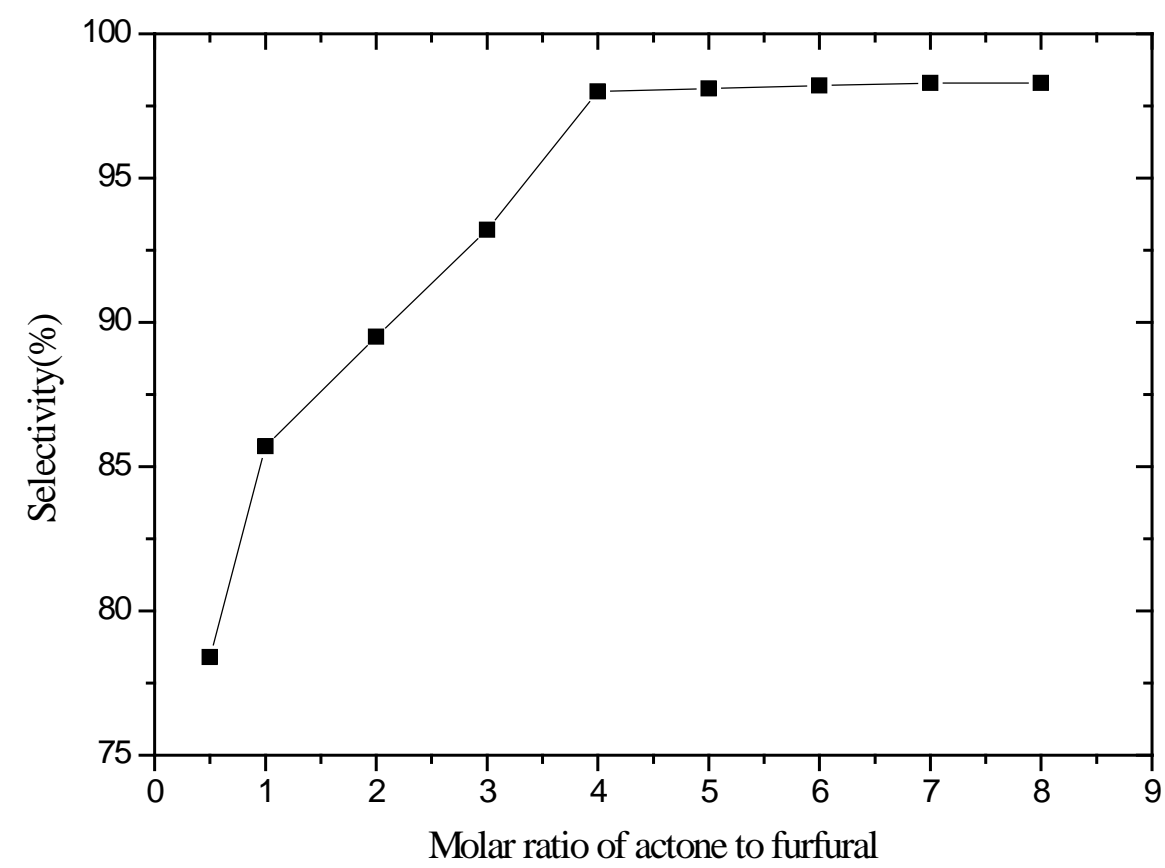

Figure 3. Effect of the molar ratio of acetone to furfural on the selectivity of FAc. Reaction conditions: $10 \%$ DBU catalyst relative to furfural molar content, reacted for $1 \mathrm{~h}$.

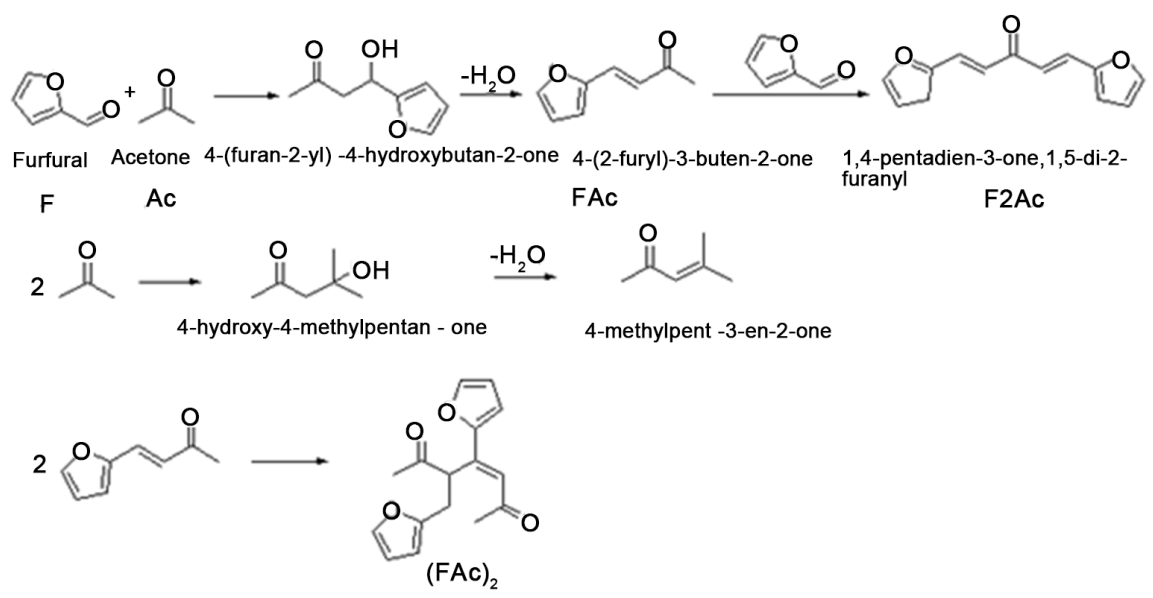

Scheme 1. Aldol condensation of furfural with acetone.

The mechanism of aldol condensation of furfural with acetone has been reported by many previous researchers. The abstraction of an $\alpha-\mathrm{H}$ atom from acetone by the basic catalyst forms an intermediate carbanion species, which reacts with the carbonyl group of furfural to form 4-(furan-2-yl)-4-hydroxybutan2-one. This species undergoes dehydration to form the unsaturated ketone 4-(2-furyl)-3-buten-2-one (FAc). A second condensation reaction of FA with another furfural molecule yields 1,4-pentadien-3-one,1,5-di-2-furanyl. It is shown that 4-(2-furanyl)-4-hydroxybutan-2-one is not detected in the aqueous condensation of furfural with acetone; The effect of the molar ratio of acetone to furfural on the selectivity (Figure 3 ) showed that the FAc yield increased little as the molar ratio was increased from 4:1 to $8: 1$. When excessive acetone is used, 
the reaction proceeds as follows:

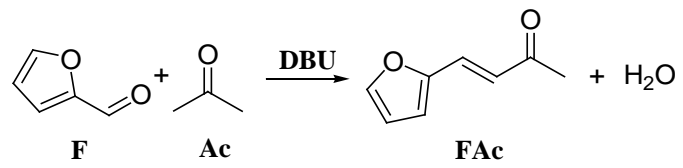

The intrinsic kinetic equation is expressed as follows:

$$
r=-\frac{\mathrm{d} C_{F}}{\mathrm{~d} t}=k C_{F}^{\alpha} C_{A C}^{\beta} C_{D B U}^{\gamma}
$$

where $k$ is the reaction rate constant; $C_{F}$ is the concentration of furfural in the reaction system; $C_{A C}$ is the concentration of acetone; $C_{D B U}$ is the concentration of $\mathrm{DBU}$; and $\alpha, \beta$, and $\gamma$ are the partial reaction orders for furfural, acetone, and DBU, respectively. The model is proposed using the following assumptions: mass transfer can be ignored because the reaction is homogeneous; the reverse reaction is neglected and changes in concentration during retro-aldol condensation are ignored; and the DBU concentration remains unchanged. The following rate equations were considered:

$$
\begin{aligned}
& r=-\frac{\mathrm{d} C_{F}}{\mathrm{~d} t}=k_{1} C_{F}^{\alpha} C_{A c}^{\beta} \\
& r=-\frac{\mathrm{d} C_{F}}{\mathrm{~d} t}=k_{1} C_{F}^{\alpha} C_{A c}^{\beta}
\end{aligned}
$$

In order to achieve a high selectivity rate, the acetone and furfural molar ratio of $10: 1$ is used.

The concentration of furfural, in terms of fractional conversion, is:

$$
\begin{gathered}
C_{F}=C_{F 0}(1-x) \\
C_{A C}=10 C_{F 0}-C_{F 0} x=C_{F 0}(10-x) \\
r=-\frac{\mathrm{d} C_{F 0}(1-x)}{\mathrm{d} t}=k_{1}\left[C_{F 0}(1-x)\right]^{\alpha}\left[C_{F 0}(10-x)\right]^{\beta} \\
\frac{\mathrm{d} x}{\mathrm{~d} t}=k_{1} C_{F 0}^{\alpha+\beta}(1-x)^{\alpha}(10-x)^{\beta}
\end{gathered}
$$

Acetone was in dramatic excess compared with furfural, permitting simplification as:

$$
\begin{gathered}
\frac{\mathrm{d} x}{\mathrm{~d} t}=k_{1} C_{F 0}^{\alpha+\beta}(1-x)^{\alpha} 10^{\beta} \\
\frac{\mathrm{d} x}{\mathrm{~d} t}=k_{2}(1-x)^{\alpha} \\
k_{2}=k_{1} C_{F 0}^{\alpha+\beta} 10^{\beta}
\end{gathered}
$$

The Arrhenius equation:

$$
k_{2}=A \mathrm{e}^{-\frac{E_{a}}{R T}}
$$


The aldol condensation of furfural and acetone was performed at the temperatures of $50^{\circ} \mathrm{C}, 60^{\circ} \mathrm{C}, 70^{\circ} \mathrm{C}, 80^{\circ} \mathrm{C}$, and $90^{\circ} \mathrm{C}$. A typical time course of the FAc conversion profile is shown in Figure 4; the formation of FAc is fast early in the reaction, before the rate of increase slows as conversion reaches $100 \%$. The rate constants $k_{2}$ were determined by fitting Equations (12) to match the experimental data. The differential equations were solved using the Runge-Kutta algorithm with a self-adjusting step. The rate constants were calculated by minimizing the sum of squares of the residuals using a non-linear least-squares algorithm based on the Marquardt method to adjust the kinetic parameters, as given in Table 1.

The first-order power-law model of kinetics with respect to acetone and furfural is a good fit for the experimental data with DBU as a catalyst. The apparent activation energy for the aldol reaction is calculated using the Arrhenius equation, after the reaction rate constants at five different temperatures were determined, as shown in Figure 5.

$$
\ln k_{2}=7.89-2.13 / T
$$

The kinetic equation of the aldol condensation of furfural with acetone catalyzed by DBU is as shown below:

$$
r=2670 \mathrm{e}^{-\frac{17.7}{R T}} C_{F}^{1}
$$

According to O'Neill et al. [15], the activation energy of the NaOH-catalyzed aldol condensation of furfural with acetone to form 4-(2-furyl)-3-buten-2-one was $55.8 \mathrm{~kJ} / \mathrm{mol}$. The apparent activation energy of the DBU-catalyzed aldol condensation in our study is clearly lower, indicating that aldol condensation is more easily performed under DBU catalysis than with a typical basic catalyst.

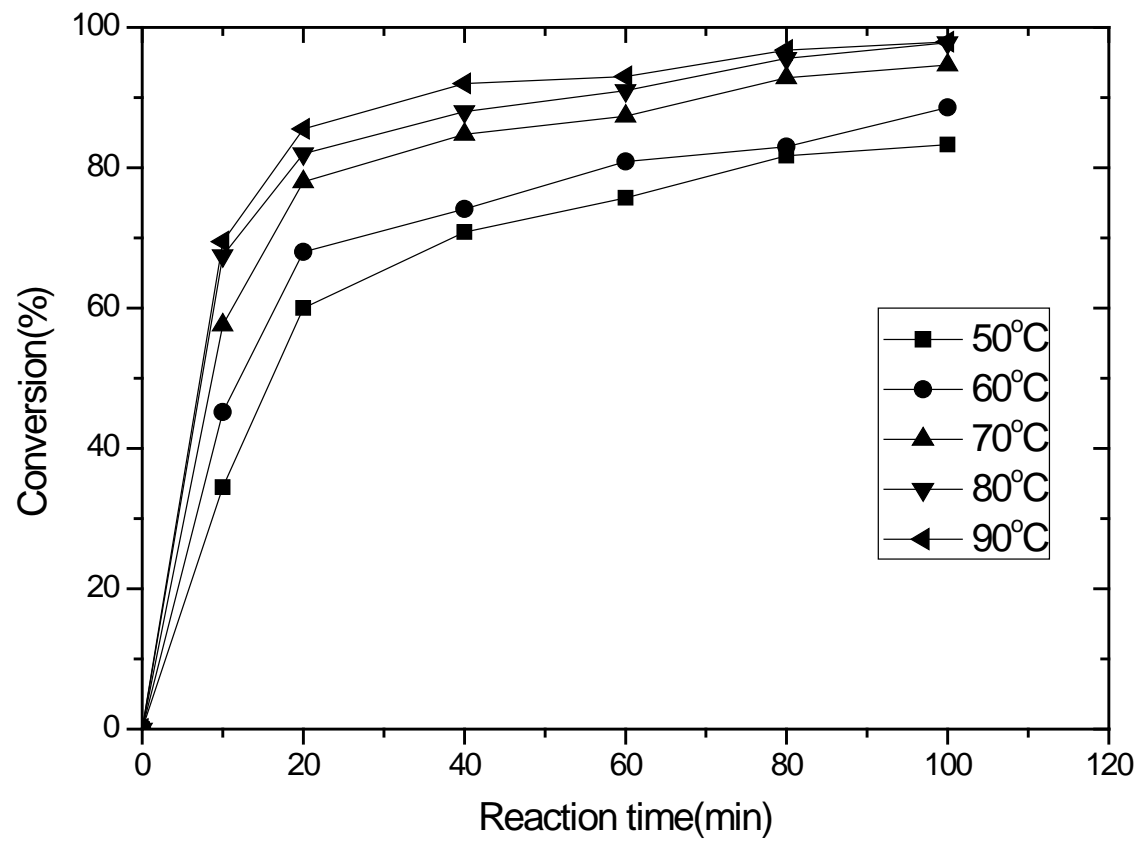

Figure 4. Relationship between conversion and reaction time at different temperatures. 


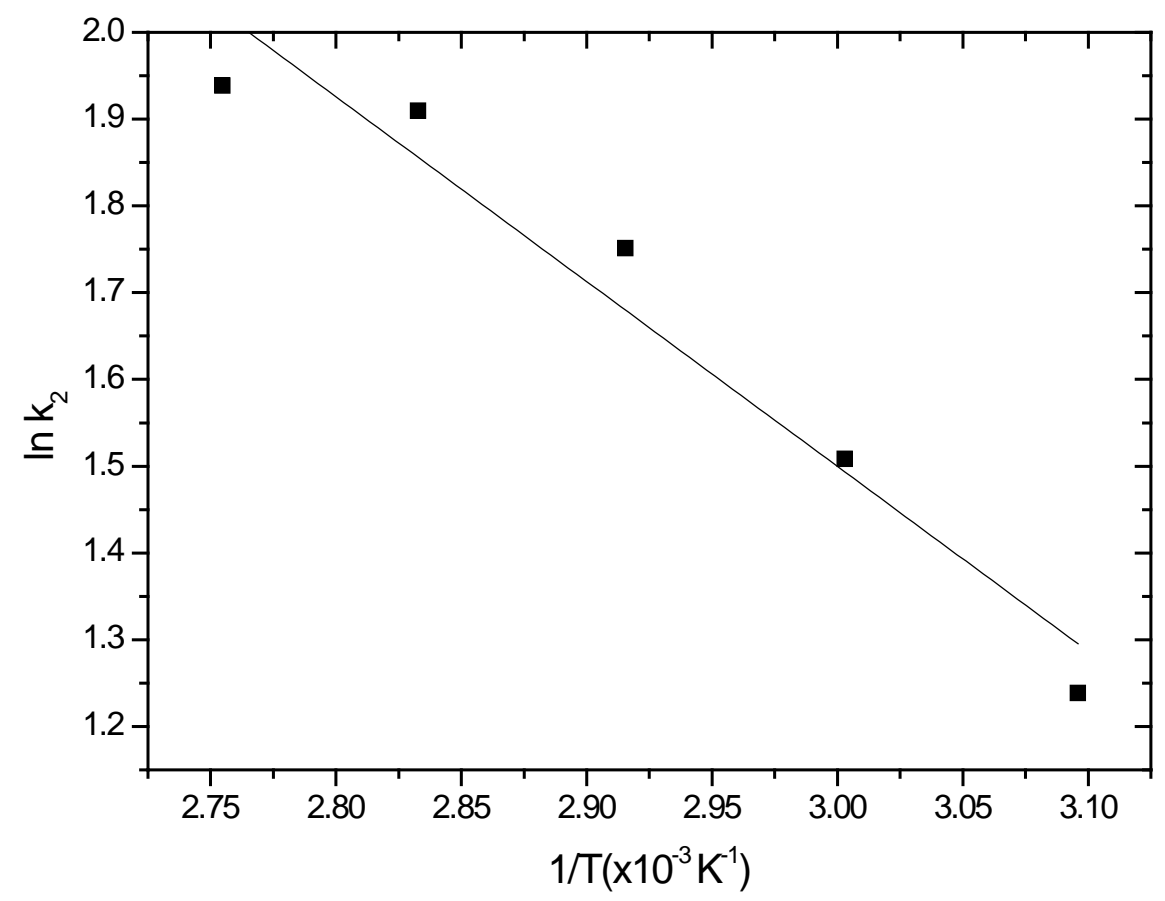

Figure 5. Prediction of $\ln \mathrm{K}$ as a function of $1 / \mathrm{T}$.

Table 1. Reaction rate constants for aldol condensation of furfural with acetone catalyzed by DBU.

\begin{tabular}{cccc}
\hline$T(K)$ & $\mathrm{k}_{2}$ & $\alpha$ & $R^{2}$ \\
\hline 323 & 3.45 & 0.98 & 0.99 \\
333 & 4.52 & 0.96 & 0.98 \\
343 & 5.76 & 1.0 & 0.99 \\
353 & 6.75 & 0.97 & 0.99 \\
363 & 6.95 & 0.99 & 0.98 \\
\hline
\end{tabular}

\subsection{Conclusion}

In this study, DBU was identified as an effective homogeneous catalyst for the aldol condensation of furfural and acetone in a closed system composed of acetone and DBU. The first-order power-law model of kinetics with respect to acetone and furfural fitted the actual experimental data well, with $R^{2}=0.98$. In a single-phase solution, the reaction began with the deprotonation of acetone to form a carbanion intermediate, which then reacted with the carbonyl group of furfural to form FAc with high selectivity. DBU is a promising catalyst to produce FAc monomers, which can be transformed by hydrogenation and deep hydrodeoxygenation into fuels.

\section{Acknowledgements}

The financial support from the National Natural Science Foundation of China (No. 21602206) is gratefully acknowledged. 


\section{References}

[1] Diefenderfer, J., Arora, V. and Singer, L.E. (2016) International Energy Outlook 2016 Liquid Fuels. 202-586.

[2] Hronec, M., Fulajtárova, K., Liptaj, T., Prónayová, N. and Soták, T. (2015) Bio-Derived Fuel Additives from Furfural and Cyclopentanone. Fuel Processing Technology, 138, 564-569. https://doi.org/10.1016/j.fuproc.2015.06.036

[3] Li, X., Jia, P. and Wang, T. (2016) Furfural: A Promising Platform Compound for Sustainable Production of C4 and C5 Chemicals. ACS Catalysis, 6, 7621-7640. https://doi.org/10.1021/acscatal.6b01838

[4] Raston, C.L. and Scott, J.L. (2002) Chemoselective, Solvent-Free Aldol Condensation Reaction. Green Chemistry, 2, 49-52. https://doi.org/10.1039/a907688c

[5] Huang, X., Zhang, Q., Wang, T., Liu, Q., Ma, L. and Zhang, Q. (2012) Production of Jet Fuel Intermediates from Furfural and Acetone by Aldol Condensation over $\mathrm{MgO} / \mathrm{NaY}$. Journal of Fuel Chemistry and Technology, 40, 973-978. https://doi.org/10.1016/S1872-5813(12)60035-8

[6] Faba, L., Díaz, E. and Ordóñez, S. (2013) Improvement on the Catalytic Performance of Mg-Zr Mixed Oxides for Furfural-Acetone Aldol Condensation by Supporting on Me-Soporous Carbons. ChemSusChem, 6, 463-473.

https://doi.org/10.1002/cssc.201200710

[7] Sadaba, I., Ojeda, M., Mariscal, R., et al. (2012) Preparation and Characterization of $\mathrm{Mg}-\mathrm{Zr}$ Mixed Oxide Aerogels and Their Application as Aldol Condensation Catalysts. ChemPhysChem, 13, 3282-3292. https://doi.org/10.1002/cphc.201200440

[8] Shen, W., Tompsett, G.A., Hammond, K.D., et al. (2011) Liquid Phase Aldol Condensation Reactions with $\mathrm{MgO}-\mathrm{ZrO}_{2}$ and Shape-Selective Nitrogen-Substituted NaY. Applied Catalysis A General, 392, 57-68. https://doi.org/10.1016/j.apcata.2010.10.023

[9] Hora, L., Kelbichová, V., Kikhtyanin, O., et al. (2014) Aldol Condensation of Furfural and Acetone over $\mathrm{Mg} \mathrm{Al}$ Layered Double Hydroxides and Mixed Oxides. Catalysis Today, 223, 138-147. https://doi.org/10.1016/j.cattod.2013.09.022

[10] Hora, L., Kikhtyanin, O., Čapek, L., et al. (2015) Comparative Study of Physicochemical Properties of Laboratory and Industrially Prepared Layered Double Hydroxides and Their Behavior in Aldol Condensation of Furfural and Acetone. Catalysis Today, 241, 221-230. https://doi.org/10.1016/j.cattod.2014.03.010

[11] Kikhtyanin, O., Kelbichová, V., Vitvarová, D., et al. (2014) Aldol Condensation of Furfural and Acetone on Zeolites. Catalysis Today, 227, 154-162.

https://doi.org/10.1016/j.cattod.2013.10.059

[12] Kikhtyanin, O., Kubička, D. and Čejka, J. (2015) Toward Understanding of the Role of Lewis Acidity in Aldol Condensation of Acetone and Furfural Using MOF and Zeolite Catalysts. Catalysis Today, 243, 158-162. https://doi.org/10.1016/j.cattod.2014.08.016

[13] West, R.M., Liu, Z.Y., Peter, M., et al. (2008) Carbon-Carbon Bond Formation for Biomass-Derived Furfurals and Ketones by Aldol Condensation in a Biphasic System. Journal of Molecular Catalysis A Chemical, 296, 18-27. https://doi.org/10.1016/j.molcata.2008.09.001

[14] Olcay, H., Subrahmanyam, A.V., Xing, R., et al. (2014) Energy \& Environmental Science, 1, 205-216.

[15] O’Neill, R.E., Vanoye, L., De Bellefon, C., et al. (2014) Aldol-Condensation of Furfural by Activated Dolomite Catalyst. Applied Catalysis B Environmental, 144, 46-56. https://doi.org/10.1016/j.apcatb.2013.07.006 